\title{
Teoria evolutiva, mídia e rock'n'roll: uma análise do videoclipe Do the Evolution
}

Edson Pereira da Silva

PhD em Genética, professor adjunto do Instituto de Biologia (Departamento de Biologia Marinha) da Universidade Federal Fluminense, chefe do Laboratório de Genética Marinha da UFF, onde trabalha com genética de populações utilizando métodos moleculares, e responsável pelo Grupo de Estudos e Pesquisas em Ensino e Epistemologia (GEPEE).

E-mail: gbmedson@vm.uff.br

Roberto Sobreira Pereira Filho

Licenciado em Ciências Biológicas, mestrando em Histórias das Ciências e da Saúde da Casa de Oswaldo Cruz/Fundação Oswaldo Cruz.

E-mail: betoquiniro@yahoo.com.br

A biodiversidade e sua origem é um tema que atrai a atenção da humanidade desde os tempos mais remotos. Originalmente considerada como obra de um Criador sábio e bondoso, a natureza era vista como perfeita, harmônica e diversa, preparada para o deleite do homem, maior obra da criação. No entanto, através de Darwin (1809-1882), a teoria da fixidez das espécies ganhou um duro golpe. A teoria darwiniana definia a evolução como um atributo da história da vida no planeta, sendo um processo não teleológico e totalmente contingente, independente de um Diretor. Mais que isso, colocava o homem no mesmo patamar dos outros seres vivos, enfatizando sua origem comum.

A moderna teoria evolutiva - teoria sintética da evolução, criada na década de 1930, a partir da contribuição de vários cientistas, entre os quais se destacam o americano Sewall Wright e os britânicos Ronald Fisher e John Haldane $^{1}$ - incorpora às idéias de Darwin os conhecimentos da Genética. Assim, segundo a teoria sintética, a evolução é a mudança da composição genética das populações, ao longo das gerações. Essa mudança se dá a partir da ação de forças que produzem variação gênica (mutação e migração) e forças que alteram as proporções dos variantes nas populações (seleção natural e deriva genética). Duas conclusões são muito importantes a respeito do processo evolutivo tal como descrito por essa teoria. Primeira, como toda geração nova é produzida por um sorteio dos genes da geração anterior, então, em cada geração vai haver uma mudança nas proporções dos genes, apenas pelo acaso. Essa oscilação ao acaso nas proporções dos genes ao longo das gerações é

1. GOULD, Stephen Jay. Darwin e os grandes enigmas da vida. 2. ed. São Paulo: Martins Fontes, 1999. 274 p. LEWONTIN, Richard. The genetic basis of evolutionary change (As bases genéticas da mudança evolucionária). New York: Columbia University Press, 1974. 346 p. MAYR, Ernest; PROVINE, William B. (Eds.). The evolutionary synthesis: perspectives on the unification of Biology (A síntese evolucionária: perspectivas sobre a unificação da Biologia). Cambridge, Massachusetts: Harvard University Press, 1998. $487 \mathrm{p}$. 
denominada deriva genética; portanto, segundo os termos da teoria sintética, a evolução é um fato natural, se dá todo o tempo e é impossível pensar em uma população que não esteja evoluindo. Não é preciso nem mesmo a seleção natural para que a evolução ocorra, embora sua existência facilite e otimize o processo. Desse modo, o processo evolutivo tem como resultado a ramificação das diferenças, seja entre indivíduos dentro da mesma população, seja em populações dentro da mesma espécie, seja ainda em espécies dentro do mesmo gênero, e assim por diante. Como a evolução pode se dar pela ação de forças como o acaso (mutação, deriva) e a seleção natural, ou seja, atendendo a pressões imediatas do ambiente, o processo evolutivo não possui um planejamento. De fato, para gerar toda a biodiversidade observada hoje, o processo evolutivo dependeu de um período de tempo muito longo e muitas extinções. Logo, a segunda conclusão é de que idéias como perfeição e progresso não são adequadas para descrever o processo evolutivo. Como se pode notar, a moderna teoria evolutiva mantém as novidades da teoria darwiniana e radicaliza suas conclusões.

A despeito de a moderna teoria evolutiva ser um assunto técnico, o interesse por ela extrapola os muros da academia e dos laboratórios de pesquisa e alcança tanto os debates filosófico-religiosos quanto a curiosidade do leigo. Os conceitos da teoria sintética são alvo dos mais diversos meios de comunicação, como, por exemplo, TV, revistas em quadrinhos, cinema etc. Contudo, em quase todos esses casos, os postulados e evidências da moderna teoria evolutiva são abordados de forma pouco precisa no que diz respeito ao seu caráter propriamente científico. O que observamos, muitas vezes, é a mídia de massas veiculando informações sensacionalistas e fora de contexto, mais interessada na lógica da oferta e da procura, inerente ao mercado do qual faz parte, do que com a precisão científica dos conteúdos veiculados.

Entender a relação da mídia com os sujeitos que recebem, interpretam e incorporam seu discurso é compreender que esta se dá através de uma satisfação de necessidades geradas pela própria mídia, que trabalha na destruição das identidades dos sujeitos ao construir múltiplas identidades e posições que se reforçam mutuamente em direção aos seus próprios ideais. A natureza e a confiabilidade do conhecimento abordado são menos importantes que as vantagens mercadológicas. Contudo, numa perspectiva mais otimista, podemos entender que a veiculação de temas científicos, como a teoria evolutiva, em filmes, quadrinhos, videoclipes, novelas etc., tem a vantagem de divulgar esses temas. Embates teóricos sobre fronteiras éticas e indagações acerca do futuro da ciência e seu papel dentro da sociedade deixam de estar, assim, restritos aos círculos de cientistas e pesquisadores para chegar aos cidadãos. Independentemente de qual das perspectivas acima possa ser assumida, o fato é que a realidade está permeada de conhecimento científico, objetos de mídia e suas relações, especialmente no caso de temas polêmicos como a moderna teoria evolutiva. Mais que isso, tanto a mídia quanto a ciência, na medida em que operam produções discursivas, passam a compor ou recompor 
elementos significativos da cotidianidade, essencialmente discursiva, e dessa forma criam visões e versões de mundo que constituem nossas práticas e concepções sociais e culturais.

Dentre os diversos materiais veiculados pelos meios de comunicação de massas que abordam questões como estas, o videoclipe Do the Evolution é um exemplo. Produzido a partir de uma canção homônima do grupo de rock norte-americano Pearl Jam, o vídeo é uma animação sobre a evolução humana que apresenta um profundo questionamento a respeito do futuro. Esse videoclipe é extensamente divulgado pela mídia, em especial no canal de televisão MTV.

Conscientes da problemática que envolve a mídia de massas, o conhecimento científico e sua influência na nossa realidade, decidimos realizar uma análise do videoclipe Do the Evolution e tentar entender como tais questões estão presentes nesse material. Mais que isso, por ser a teoria sintética da evolução um conteúdo importante do ensino médio, faixa etária alvo do videoclipe, acreditamos que o presente trabalho pode ter um lugar na sala de aula.

Nossa análise de Do the Evolution inclui tanto o próprio videoclipe quanto a canção em separado. Para a análise do primeiro, foram usados como referenciais teóricos os trabalhos de Maurice Merleau-Ponty² e Sérguei M. Eisenstein ${ }^{3}$, e, para a discussão das idéias presentes na canção, utilizamos o trabalho de Décio Pignatari ${ }^{4}$.

\section{LUZ, CÂMERA, EVOLUÇÃO!}

Encontramos no ensaio de Merleau-Ponty uma reflexão sobre a ligação entre som e imagem no cinema. Um filme mudo acrescido de sons não é o mesmo que um filme com áudio normal. Poderíamos associar, por exemplo, o filme mudo "A" aos sons "B" e o resultado de suas interações como "A+B". De maneira diferente, um filme já produzido com sons constituiria "C", um elemento único, no qual, para além das interações possíveis entre registros distintos (som e imagem), encontramos aquilo que Sergei Eisenstein denomina de valor de outra dimensão, um conceito.

Seguindo esse raciocínio, entendemos que Do the Evolution apresenta duas possibilidades de interpretação: uma baseada no videoclipe, como um conceito, e outra fundamentada exclusivamente na canção, nesse caso tomada, também, como unidade: a mensagem poética. Segundo Décio Pignatari, essa unidade que combina melodia e letra deve ser interpretada de forma analógica, em que não é possível separar o conteúdo da forma.

A análise dessas duas unidades - o conceito no videoclipe e a mensagem poética na canção - tem como conseqüência direta o fato de que elas podem apresentar mensagens não necessariamente iguais. No caso específico de Do the Evolution, esses registros parecem, inclusive, contraditórios: enquanto observamos uma visão fatalista/desesperançosa no videoclipe, na canção parece patente uma perspectiva irônica/contestatória.
2. MERLEAU-PONTY, Maurice. O cinema e a nova psicologia. In: GRUNNEWALD, José Lino (Org.). A idéia do cinema. Rio de Janeiro: $\mathrm{Ci}$ vilização Brasileira, 1969. 152 p. cap. 1, p. 17-32.

3. EISENSTEIN, Sergei. O princípio cinematográfico e o ideograma. In: GRUNNEWALD, José Lino (Org.). A idéia do cinema. Rio de Janeiro: Civilização Brasileira, 1969. 152 p. cap. 5, p. 99-114.

4. PIGNATARI, Décio. O que é comunicação poética. São Paulo: Brasiliense, 1987. 63 p. (Primeiros Passos). 


\section{VIDEOCLIPE}

Nas primeiras cenas com referência direta à evolução do homem, um pequeno primata utiliza um graveto para se alimentar de formigas (Figura 1). Logo em seguida, um outro primata, de maior tamanho, pisa neste primeiro e sorri triunfante para, então, ser acertado na nuca por um hominídeo, que vai receber pedradas de outros hominídeos, mais semelhantes aos homens atuais, os quais riem da situação.

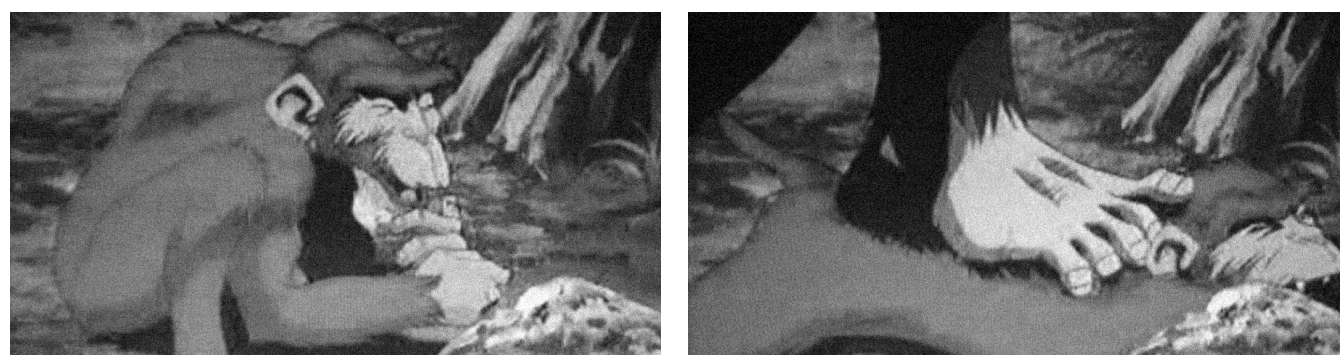

5. SILVA E SÁ, Guilherme José da. Da cultura da diferença à diferença das culturas: reflexão sobre a apropriação do conceito de cultura no discurso de primatólogos Trabalho apresentado no Seminário Ciências Sociais e Biologia em Cenários Contemporâneos: Repensando Fronteiras e Interfaces, organizado por ANPOCS. Rio de Janeiro, 2004
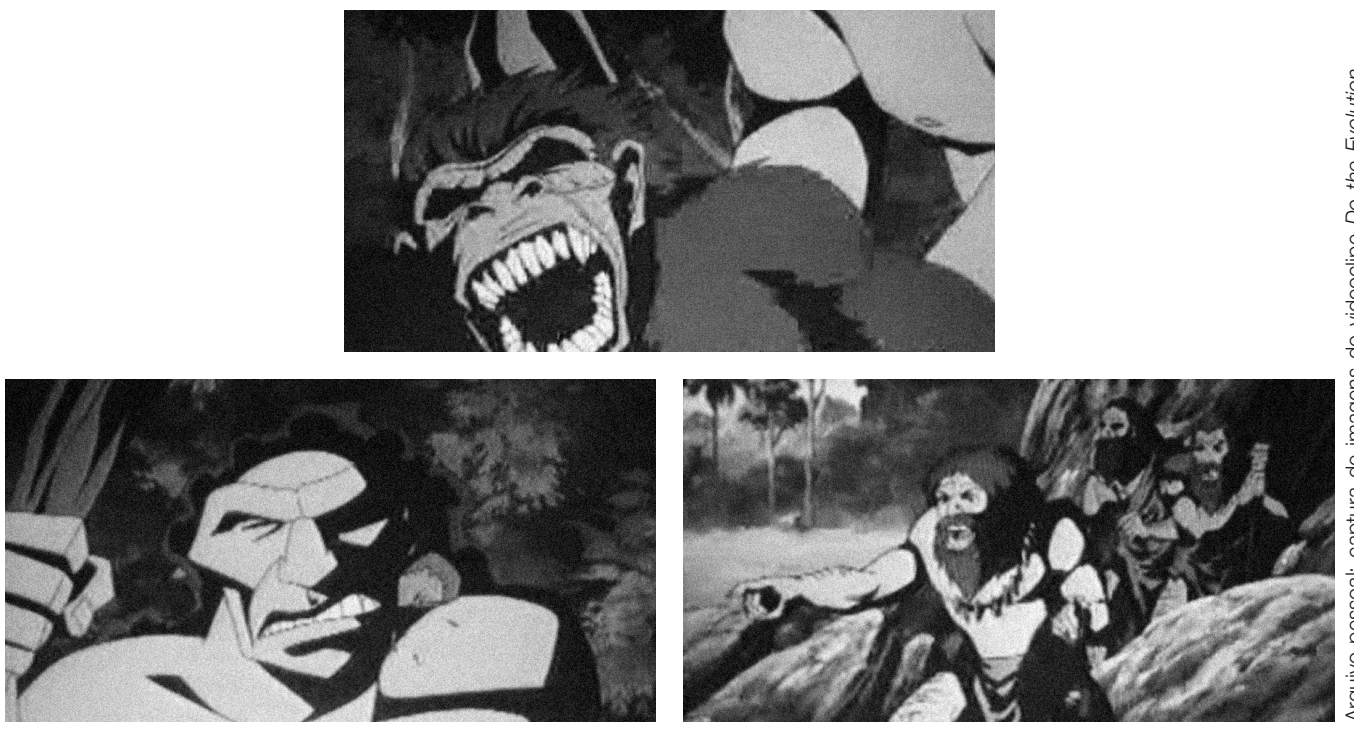

Figura 1

Podemos atentar à representação de diferentes espécies, suas ações e como se relacionam. O primata de menor tamanho, remexendo em um formigueiro com um graveto, se associa à espécie humana, visto que o uso de ferramentas, uma técnica tida como manifestação cultural, pode ser considerado um aproximador filogenético dos símios em relação aos humanos ${ }^{5}$. A montagem dessa seqüência nos sugere uma alegoria da evolução desde os pequenos primatas até o homem, representado no final pelos hominídeos vestidos. As cenas encerram uma forte visão antropocêntrica; os homens atuais são os últimos na seqüência, subjugando os indivíduos menos evoluídos representados anteriormente. A mensagem expressa é a da superioridade humana e sua posição de mais evoluída. Surgindo por último, o homem parece ser, ainda, a finalidade da evolução.

Uma das maneiras pelas quais os alunos desenvolvem concepções errôneas a respeito da evolução é quando associam, de maneira lógica, informações que 
Teoria evolutiva, mídia e rock'n'roll - Edson P. da Silva e Roberto S. Pereira Filho

aprendem na escola com conceitos equivocados ${ }^{6}$. Por exemplo, alunos que associam a evolução biológica ao progresso irão associar a força da seleção natural à idéia de um propósito para evolução. $\mathrm{O}$ homem na última cena sugere que a evolução tem uma finalidade: a condição humana. Esse tipo de concepção é muito comum e um dos maiores obstáculos para a aceitação da contingência como uma força relevante para a evolução. A associação progresso/finalidade com a evolução biológica está presente em todo o videoclipe.

Diferentemente da Figura 1, na qual o sentido de finalidade encontra-se mais evidente, a Figura 2 explicita uma forte idéia de progresso associada à evolução.
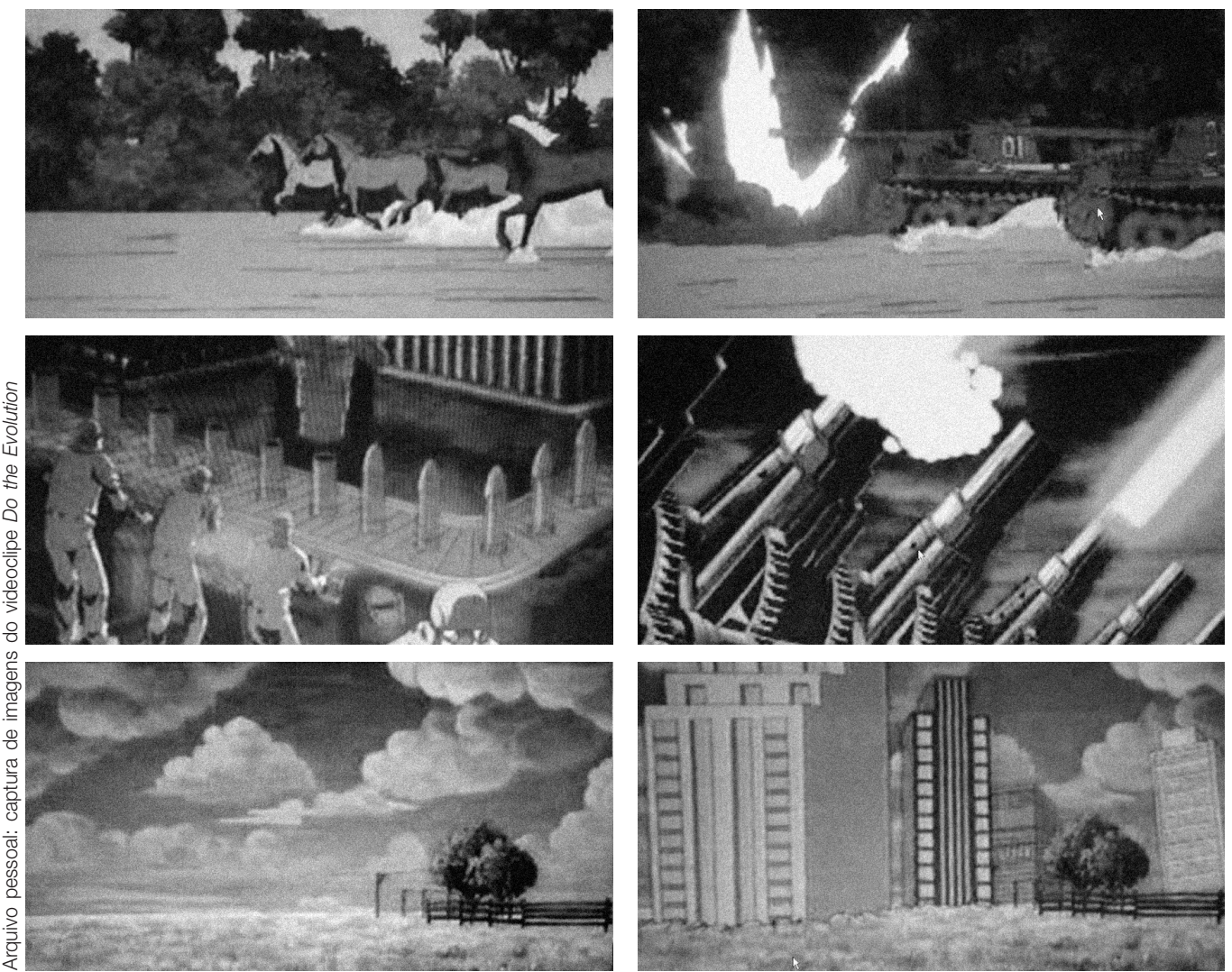

Figura 2

As quatro primeiras cenas, tanto as que demonstram uma substituição de cavalos por tanques, quanto as de uma indústria de armas e sua utilização, parecem fazer referência à idéia de que o progresso científico e tecnológico conduz à guerra e à destruição. A noção de progresso apresentada nas cenas tem uma conotação negativa, ao contrário da noção positiva comumente associada à palavra progresso. Embora o significado das cenas esteja relacionado com avanço, um andar para a frente, o videoclipe parece querer demonstrar que esse avanço conduz a um futuro sombrio. A idéia de futuro sombrio se apresenta ao longo de todo o videoclipe: a evolução (= progresso) levando a humanidade (= evoluída) rumo à destruição, à guerra e ao sofrimento - idéias reforçadas através de imagens e cores que provocam uma sensação de descon-

6. ALTERS, Brian; NELSON, Craig E. Teaching evolution in higher education (Ensinando evolução no ensino superior). Evolution: The Society for the Study of Evolution, $\mathrm{n}$. 56, p. 1891-1901, October 2002. 
7. JAMESON, F. O marxismo realmente existente. In: GAZZOLA, Ana Lúcia Almeida (Org.). Espaço e imagem: teorias do pósmoderno e outros ensaios de Frederic Jameson. Rio de Janeiro: Editora UFRJ 2004. 292 p. cap. 3, p. 67-106

8. HARVEY, David. Condição pós-moderna. São Paulo: Loyola, 1999. 349 p. forto. Por exemplo, enquanto na cena dos cavalos um céu mais claro e aberto aparece ao fundo, na seguinte, surgem os tanques e a exibição de um horizonte vermelho e escuro com a mesma tonalidade das cenas da indústria de armas e dos canhões. Apelo observado, também, na cena em que alguns prédios surgem abruptamente onde antes predominava o verde e a natureza.

Tanto no primeiro caso (Figura 1) quanto nas cenas destacadas anteriormente (Figura 2), o significado implícito de evolução é o de progresso, nesta noção específica: aquele que ruma ao poder e à dominação dos mais fortes sobre os mais fracos. Na Figura 1, os indivíduos apresentados como mais evoluídos subjugam os que não alcançaram essa condição: dominação e poder sobre os representados como menos evoluídos. Na Figura 2, a temática principal é a guerra. A mesma idéia, porém, agora representada por armas, tanques e bombas em vez de um porrete ou uma pedra. O progresso (= evolução), nesse caso, está ligado às novidades científicas e tecnológicas (armas e equipamentos sofisticados). Podemos, ainda, perceber as conseqüências lógicas dessa associação feita pelo videoclipe entre evolução-progresso-poder: se a evolução é um processo natural que leva ao progresso, tendo como resultado o poder, a dominação e a subjugação, estes são, portanto, processos naturais que devem ser aceitos como inapeláveis. Ou seja: a dominação e o exercício do poder nada mais são que leis naturais, pois estão intrinsecamente ligados à evolução dos seres vivos, que é um processo natural.

A naturalização, ou seja, explicar os problemas causados pela sociedade como resultado de leis naturais constitui uma ideologia de resignação ao status quo. Frederic Jameson ${ }^{7}$, por exemplo, entende que o desenvolvimento do capitalismo atual inclui a ideologia de resignação ao inevitável como única práxis diante dos problemas sociais. A temática de prevalência do mais poderoso, do mais forte ou do mais evoluído no videoclipe pode ser encarada como um reflexo dessa ideologia. A evolução dos seres vivos cai como uma luva para essa retórica.

Além das idéias de progresso e finalismo, o videoclipe transmite uma perspectiva fatalista e determinista em relação à natureza humana e às ações sociais, com um olhar extremamente pessimista em relação ao futuro. As cenas destacadas na Figura 3 nos ajudarão a refletir sobre a questão.

A imagem dos homens atrás de cercas lembra os campos de concentração da Segunda Guerra Mundial, bem como a gigantesca explosão final parece ser uma referência às armas nucleares utilizadas naquela ocasião. Essas referências à guerra e ao mau uso do conhecimento tecnológico são um sintoma de desconfiança em relação à ciência e suas promessas de dias melhores para a humanidade. David Harvey ${ }^{8}$, por exemplo, lembra-nos de que a idéia da ciência como panacéia da humanidade nasceu com o projeto Iluminista, o qual trazia uma promessa de vitória sobre a natureza e seus segredos, dando à humanidade a esperança de um futuro perfeito. Como não foi a isso que se assistiu nos séculos seguintes, com a deflagração de guerras e uma série de revoluções e revoltas por todo o mundo, a humanidade, segundo o autor, começou a entender que a razão iluminista não estava conduzindo ninguém a lugar algum. $\mathrm{O}$ resultado foi uma profunda aversão a todo projeto que buscasse a emancipação humana a partir da tec- 

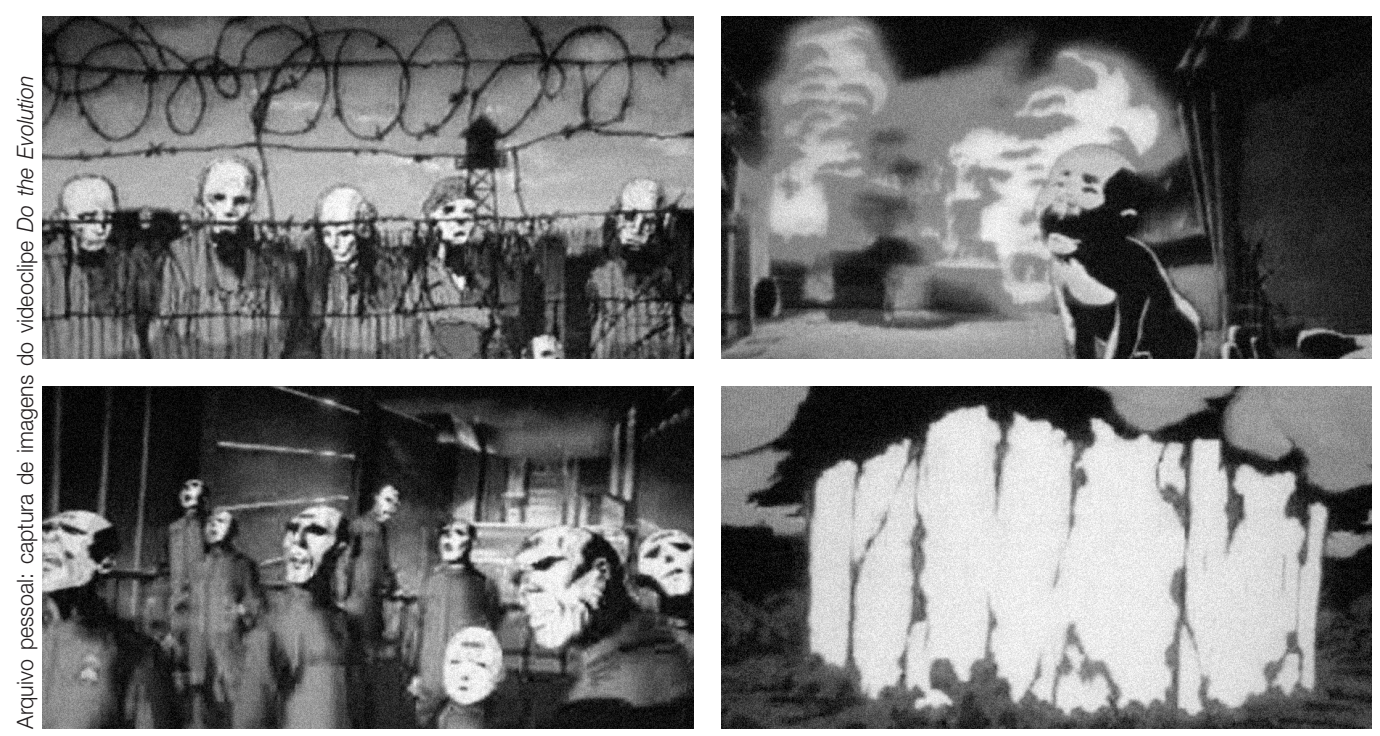

Figura 3

nologia, da ciência e da razão. Esse sentimento pós-moderno de abandono e decepção em relação ao futuro é o que Harvey define como distopia, ou seja, uma idéia pessimista de futuro, geralmente associada a um fatalismo. Do the Evolution está em coro com essa perspectiva pós-moderna descrita por Harvey, quando expõe cenas relacionando o progresso da humanidade com guerras e sofrimento, associando de forma estrita o desenvolvimento tecnológico ao bélico.

\section{A CANÇÃO}

Acreditamos que as mensagens do videoclipe e da canção não são homogêneas. A seguir, destacaremos alguns trechos da canção para que possamos ilustrar nosso argumento.

I'm ahead, I'm a man

I'm the first mammal to wear pants, yeah

I'm at peace with my lust

I can kill 'cause in God I trust, yeah

It's evolution, baby

[Eu estou à frente, eu sou um homem

Eu sou o primeiro mamífero a usar calças, yeah,

Eu estou em paz com minha luxúria

Eu posso matar porque em Deus eu confio, yeah

É evolução, baby, yeah]

Embora neste trecho seja marcante o tom de prepotência, esta, contudo, é também irônica. É uma falsa arrogância, uma forma de debochar das demais idéias expressas ao longo da canção que, através deste recurso, acabam sendo colocadas em xeque e deslegitimadas. Dessa forma, há uma contestação do determinismo que define certos valores como produtos de um processo natural: 
o processo evolutivo. Por exemplo, quando é mencionado que o homem está à frente e é o primeiro mamífero a usar calças, está se ridicularizando a idéia de definir mais evoluído pela produção e uso de alguns objetos culturais, nesse caso, as calças. Por um lado, as características apresentadas não representam nada que esteja associado ao processo evolutivo. Por outro lado, o próprio fato de que estas características possam estar associadas ao processo evolutivo é relativizada. De modo que, onde ouvimos "It's evolution, baby", ecoa a interrogação: "Is it evolution, baby?" ou mesmo "It's not evolution, baby!". Nesse sentido, a interpretação pode ser contrária a uma associação dessas características (estar à frente, usar calças etc.) à evolução e pode representar uma denúncia (debochada, irônica, talvez, até, desencantada) da estupidez que estas coisas representam.

I am ahead, I am advanced

I'm the first mammal to make plans

I crawled the earth, now I'm higher

Twenty ten, watch it go to fire

It's evolution, baby

Do the evolution

C'mon, c'mon, c'mon'

[Eu estou à frente, eu sou evoluído

Eu sou o primeiro mamífero a fazer planos

$\mathrm{Eu}$ rastejei na terra, agora eu sou mais alto

Dois mil e dez, veja incendiar

É evolução, baby

Faça a evolução

Vamos, vamos, vamos]

Mantendo a ironia e adicionando um sentimento de revolta, a canção chega à sua conclusão: é preciso entender que isso não é evolução, não é um processo natural! Relacionando a evolução biológica a previsões apocalípticas, a canção está, como esteve todo o tempo, denunciando o que é, de fato, uma naturalização ideológica das atitudes humanas.

Esperamos que estes dois trechos tenham demonstrado o nosso ponto: as mensagens veiculadas pelo videoclipe e pela canção parecem estar em contradição. Mais que isso, a canção permite uma polissemia interpretativa ao ouvinte, que o videoclipe nega ao espectador.

\section{E O PROFESSOR COM ISSO?!}

Esta deve ser a pergunta que você está se fazendo depois de ler essa pequena análise do videoclipe e da canção Do the Evolution. Acreditamos que a análise de um produto de mídia, tentando entender as relações entre este e o conhecimento científico por ele apropriado, pode ser útil em sala de aula.

Mas as idéias desse videoclipe poderiam ter alguma influência sobre as opiniões dos alunos ou sobre sua apreensão dos conteúdos referentes à teoria evolutiva? Achamos que, apesar de alguns limites, Do the Evolution (videoclipe 
Teoria evolutiva, mídia e rock'n'roll - Edson P. da Silva e Roberto S. Pereira Filho

e canção) pode ter um papel relevante na discussão de conteúdos de Biologia, bem como uma influência sobre as opiniões dos alunos. A semelhança entre as palavras evolução e evolution alertam o ouvinte para o que está por vir e, mais que isso, o aluno ou fã interessado chega, minimamente, ao videoclipe, o que já é suficiente para o entendimento de parte da mensagem. Além disso, as imagens da animação são óbvias para o espectador. Do the Evolution consegue, assim, explicitar suas idéias, mesmo para aqueles que não entendem inglês.

Ainda assim, o leitor pode fazer a pergunta: por que trabalhar com um videoclipe de uma canção em inglês?! Pensamos em utilizar Do the Evolution como uma forma de aproximação à realidade dos estudantes. A banda Pearl Jam é um ícone jovem. O rock é uma música jovem. Dessa maneira, acreditamos que uma possível forma de despertar o interesse desses jovens para o debate de questões, que antes seriam encaradas apenas como escolares, seria utilizando-se de realidades com as quais eles estão familiarizados. Sabemos que, mesmo cantando em outro idioma, muitos grupos de rock exercem notável influência nos fãs brasileiros. Demonstrar aos alunos que eles podem debater essas questões sem sair de sua realidade e sem precisar estudar para prova é, talvez, uma maneira de fazê-los aproximar-se da sala de aula e de seus conteúdos.

A diferença que destacamos entre as idéias presentes no videoclipe e na canção pode ser uma maneira de discutir com os alunos a polissemia presente nos produtos de mídia. No caso específico do nosso trabalho, a visão fatalista do videoclipe pode ser confrontada com a contestação presente na canção, construindo uma discussão entre o conformismo que representa a aceitação da realidade e a possibilidade de mudança das situações colocadas. Apesar de parecer uma idéia óbvia demais para ser citada, é importante considerar a recepção acrítica dada por parte dos jovens aos conteúdos midiáticos. Nossa proposta ganha valor a partir do momento em que se dispõe a desvelar intenções que permaneceriam ocultas à primeira vista, contribuindo para uma maior reflexão acerca dos produtos da mídia em geral.

Além disso, Do the Evolution é um material que traz grandes possibilidades de abordagens multi, trans e interdisciplinares. Disciplinas como História e Geografia (pelas abordagens históricas e referências a entidades políticas do presente), Português (pelo exercício de interpretação que pode ser explorado tanto na canção quanto no videoclipe), Filosofia (pela ética) e a própria disciplina de Língua Estrangeira (pelo fato de a canção ser em inglês) podem ser exploradas em solo ou em conjunto com a Biologia. Atividades que integram disciplinas abrem espaço para um trabalho conjunto entre os professores e demonstram, para o aluno, a forma como o conhecimento está interligado.

Estas idéias não são nenhuma novidade e, também, não pretendem privilegiar a utilização de produtos da mídia de massas em sala de aula em detrimento de outras abordagens; no entanto, servem como demonstração das 
diferentes possibilidades e recursos que se é possível ter ao trabalhar com este tipo específico de produto, o qual tem como vantagem estar fortemente inserido na realidade dos jovens que freqüentam as salas de aula. Nosso trabalho não quer ser nada mais do que um exemplo de como essas possibilidades podem ser exploradas, tentando acrescentar aos métodos tradicionais de ensino perspectivas capazes de atrair a atenção dos alunos.

Resumo: A teoria evolutiva é um dos pilares das ciências da vida e, em parte por causa disso, tem as suas idéias exploradas pelos mais diversos meios de comunicação. Contudo, como as lógicas que presidem as produções discursivas da mídia e ciência atendem a temporalidades e contextos diferentes, as mensagens de uma e outra, muitas vezes, revelam um afastamento. Neste trabalho, o videoclipe Do the Evolution do grupo de rock Pearl Jam é analisado focalizando essa preocupação. Ficou evidente que o videoclipe faz uma associação entre evolução biológica e progresso, numa perspectiva distópica do futuro. Por outro lado, a análise da canção homônima mostrou uma atitude irônica e debochada em relação ao status quo. A partir dessa leitura, entendemos que Do the Evolution é um material que pode ser usado didaticamente em sala de aula.

Palavras-chave: ensino de Biologia, teoria evolutiva, material didático, educação nãoformal, mídia de massas.
Abstract: The evolutionary theory is one of the pillars of the life sciences and due to this it has been appropriated by mass media in many different ways, although not always respecting its scientific messages. This assay deals with this problem in the Do the Evolution clip from the rock band Pearl Jam. The analysis revealed that the clip shows an association between evolution and progress with a pessimistic view of the future. The song, however, put forward an ironic message in relation to the status quo. We conclude that Do the Evolution has potential to be used as a didactic material in Biology classes as well as for other subjects.

Keywords: Biology education, evolutionary theory, didactic material, non-formal education, mass media. 